FERMIIAB-Conf-92/122

(SSCL-Preprint-108)

\title{
Mechanical Behavior of Fermilab/General Dynamics Built 15M SSC Collider Dipoles
}

\author{
M. Wake, M. Bleadon, R. Bossert, J. Carson, S. Delchamps, S. Gourlay, R. Hanft, \\ W. Koska, M. Kuchnir, M. Lamm, P. Mazur, D. Orris and J. Strait \\ Fermi National Accelerator Laboratory \\ P.O. Box 500, Batavia, Illinois 60510 \\ A. Devred, J. DiMarco, J. Kuzminski, W. Nah, T. Ogitsu, \\ M. Puglisi, J. Tompkins, Y. Yu, Y. Zhao and H. Zheng \\ SSC Laboratory \\ 2550 Beckleymeade Avenue, Dallas, Texas 75237
}

April 1992

Presented at the Fourth Annual 1992 International Industrial Symposium on the Super Collider, New Orleans, Louisiana, March 4-6, 1992. 


\section{Disclaimer}

This report was prepared as an account of work sponsored by an agency of the United States Government. Neither the United States Government nor any agency thereof, nor any of their employees, makes any warranty, express or implied, or assumes any legal liability or responsibility for the accuracy, completeness, or usefulness of any information, apparatus, product, or process disclosed, or represents that its use would not infringe privately owned rights. Reference herein to any specific commercial product, process, or service by trade name, trademark, manufacturer, or otherwise, does not necessarily constitute or imply its endorsement, recommendation, or favoring by the United States Government or any agency thereof. The views and opinions of authors expressed herein do not necessarily state or reflect those of the United States Government or any agency thereof. 


\title{
MECHANICAL BEHAVIOR OF FERMILAB/GENERAL DYNAMICS BUILT 15M SSC COLLIDER DIPOLES *
}

\author{
M. Wake ${ }^{\dagger}$, M. Bleadon, R. Bossert, J. Carson, S.W. Delchamps, \\ S. Gourlay, R. Hanft, W. Koska, M. Kuchnir, M.J. Lamm, \\ P.O. Mazur, D. Orris and J. Strait \\ Fermi National Accelerator Laboratory, Batavia, IL. \\ A. Devred, J. DiMarco, J. Kuzminski, W. Nah, T. Ogitsu ${ }^{\dagger}$, \\ M. Puglisi, J.C. Tompkins, Y. Yu, Y. Zhao and H. Zheng \\ SSC Laboratory, Dallas, TX.
}

\section{INTRODUCTION}

A series of full-scale demonstration SSC collider dipole magnets were built for the ASST (Accelerator System String Test). These magnets, DCA311 through DCA319, have $50 \mathrm{~mm}$ aperture and $15 \mathrm{~m}$ magnetic length with 6.6 Tesla uniform field. For the support structure of the W6733B cross section ${ }^{[1]}$, the Fermilab design uses a vertical split ${ }^{[2]}$ in the yoke. The end sections of the magnet have solid spacers and are supported by collet clamps ${ }^{[3]}$. The splices between inner and outer coils are made in preforms which lie outside of the high field region. The magnets were produced in pipeline fashion with no intentional major changes between magnets. As a part of the technology transfer program, the last 7 magnets were built by General Dynamics personnel using the magnet construction facilities of Fermilab, while the first two magnets were built entirely by Fermilab personnel.

At present, the magnets up to DCA316 have been tested at Fermilab. The general characteristics of the magnets have been quite satisfactory. Both of the Fermilab built magnets have reached the conductor limited field strength with no significant training. Two of the General Dynamics built magnets (DCA313 and DCA314) each required a single training quench. However, all of the magnets tested up to date meet the ASST specifications.

This report describes the mechanical properties of the ASST magnets at Fermilab based on the currently available test results.

\section{COIL SIZE}

Primary support of the coils is provided by stainless steel collar laminations. Upper and lower laminations are keyed together in a press to apply a pre-load to the coils. The amount

"work supported by U.S. Department of Energy

ion leave from KEK National Laboratory for High Energy Physics, Tsukuba, Japan 
of pre-load achieved depends on the coil sizes. Because of this, coil sizes must be precisely controlled.

Coil sizes were measured relative to stainless steel reference parts under $8.4 \mathrm{MPa}$ compressive force. Sizing measurements were made at 380 positions along the length of each coil. Fig. 1 and Fig. 2 show the histories of the average inner and outer coil sizes respectively. There were significant variations of the size of each coil along its length. The error bars in Fig. 1 and Fig. 2 indicate the standard deviation of coil size for of each coil.

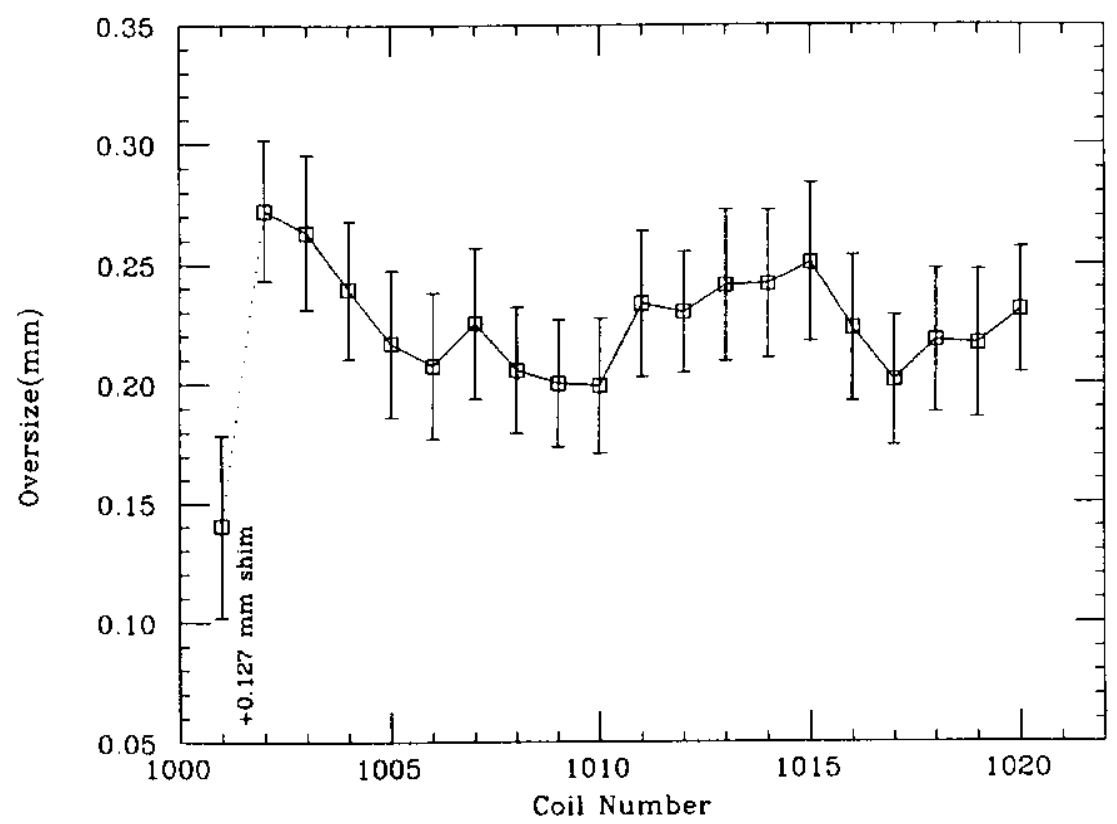

Fig. 1 Inner Coil Sire at 8.4 MPa Relative to Reference ("oversize"). Coils were paired in sequential order starting at \#1003 with the exception of \#1007, paired with \#1016 in DCA317.

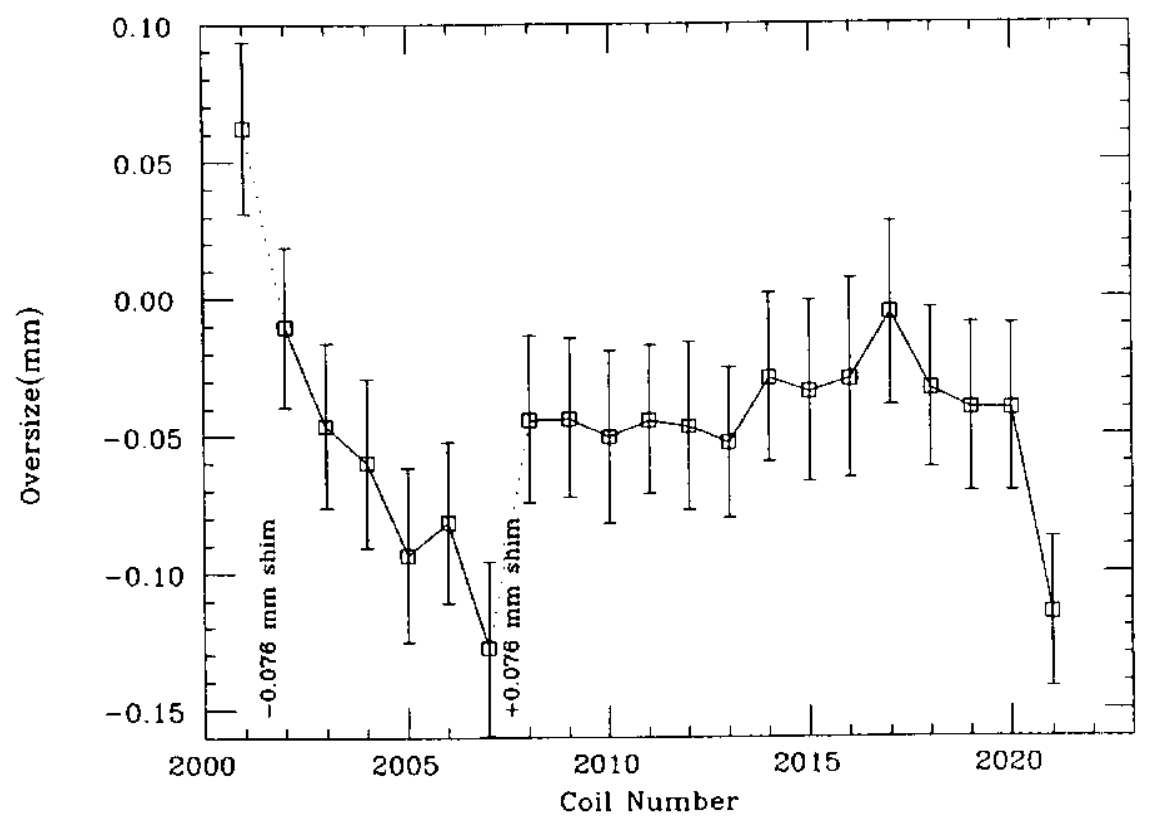

Fig. 2 Outer Coil Size at 8.4 MPa Relative to Reference ("oversize"). Coils were paired in sequential order. The size of the last coil, \#2021, was measured using a different device, so that the value shown needs a correction of $+88 \mu m$. 
As shown in Fig. 3, the coils have quite non-linear size characteristics under pressure. Therefore, the relationship between coil size and achieved pre-load is not straightforward. However, the optimum oversize values required to achieve initial pre-loads of $70 \mathrm{MPa}$ and $55 \mathrm{MPa}$ were $+0.25 \mathrm{~mm}$ and $-0.02 \mathrm{~mm}$ in the inner and outer coils respectively. These values were determined empirically from $1.5 \mathrm{~m}$ model magnet pre-load data.

Necessary adjustments to the inner and outer coil sizes were made by adding and removing shims applied to the curing tooling. Coil size seemed to decrease when a new curing die was introduced. The coil size became very stable after several coils had been cured. Variations in coil size from coil to coil could not be meaningfully correlated with cable thickness variations, which were in the range of $5 \mu \mathrm{m}$. Rather, the coil size bore the influence of the cable keystone angle, which was systematically about 0.08 degree below the design value throughout production.

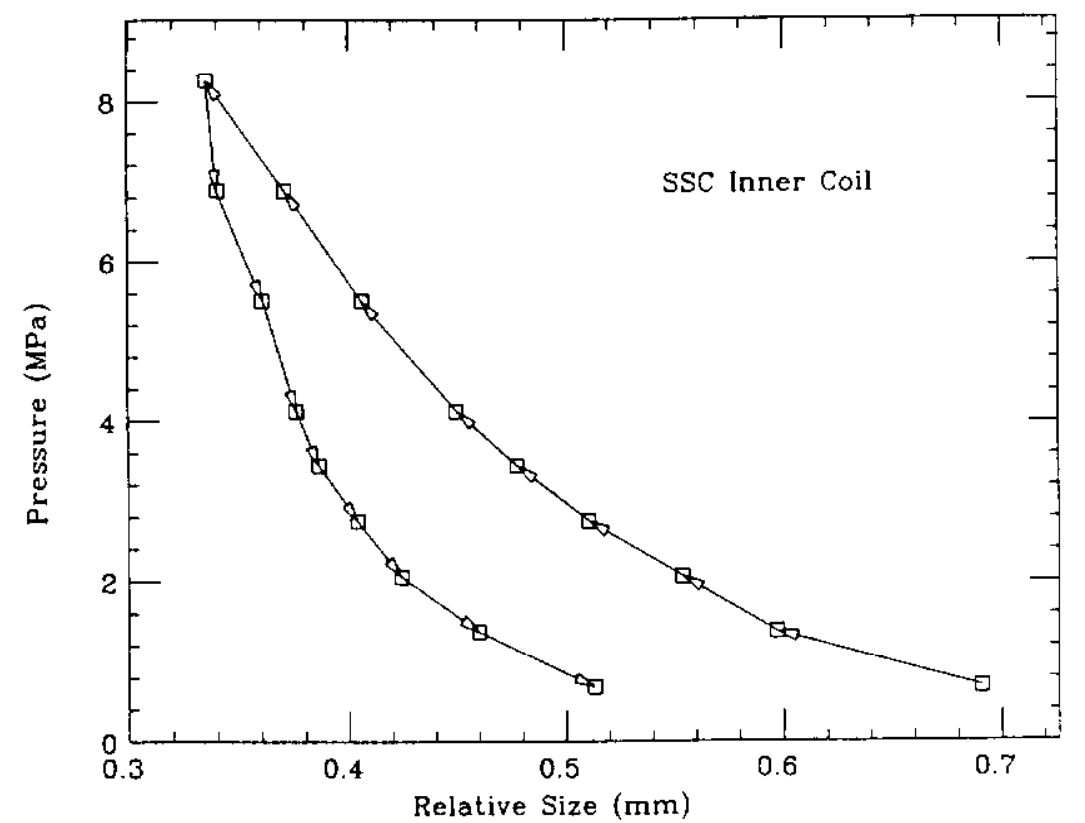

Fig. 3 Relation of Pressure and Coil Size.

Coil size non-linear in applied pressure. The large hysteresis causes a

complicated relationship with pre-load.

\section{PRE-LOADING}

The entire process of collaring and yoking was monitored by pressure gauge packages placed at the minimum and maximum size locations along the coil ${ }^{[4]}$. Each pressure gauge package measured the coil pressures of all quadrants of the inner and outer coils using beam type strain gauge transducers. The coil assembly was placed under a hydraulic press with collar lamination packs in place. Vertical pressure was applied and maintained while tapered keys were inserted by a horizontal press. The vertical pressure was kept at the same level during keying to avoid deep scratches on the keys which might lead to degradation of magnetic field uniformity. The pressure in the coils was increased by the insertion of the keys, so that the coils experienced maximum pressure during key insertion. The highest recorded value was $130 \mathrm{MPa}$, in the inner coils of DCA314. This pressure was still low enough so as not to damage the insulation. When the horizontal and vertical pressures were removed after key insertion, the coil pressure sprang back by about $20 \mathrm{MPa}$ in the inner and $30 \mathrm{MPa}$ in the outer coils. The inner and outer coil pressures crept down another $20 \mathrm{MPa}$ and $4 \mathrm{MPa}$ respectively over a few days. About $70 \%$ of the pressure loss due to creeping was recovered by yoking. The shell was welded under pressure around the yoke, resulting in a shell tension of about $200 \mathrm{MPa}$. Cool-down caused pressure losses of $30 \mathrm{MPa}$ in the inner and 15 to $20 \mathrm{MPa}$ in the outer coils, since the collared coil contracted more than the yoke and shell.

The use of anti-ovalized collars in conjunction with the vertically split yoke prevented the 
thermal contraction difference between collar and yoke from causing contact loss along the horizontal plane. A gap of $0.3 \mathrm{~mm}$ is expected at the vertical yoke/collar interface, but this should have no effect on mechanical stability.

\section{EXCITATION BEHAVIOR}

The coil pressures were also measured during the excitation of the magnet. Fig. 4 and Fig. 5 show the results. Since the vertically split design of the yoke provided support of the collars at any current, the pressure showed a smooth monotonic dependence on the square of the current.

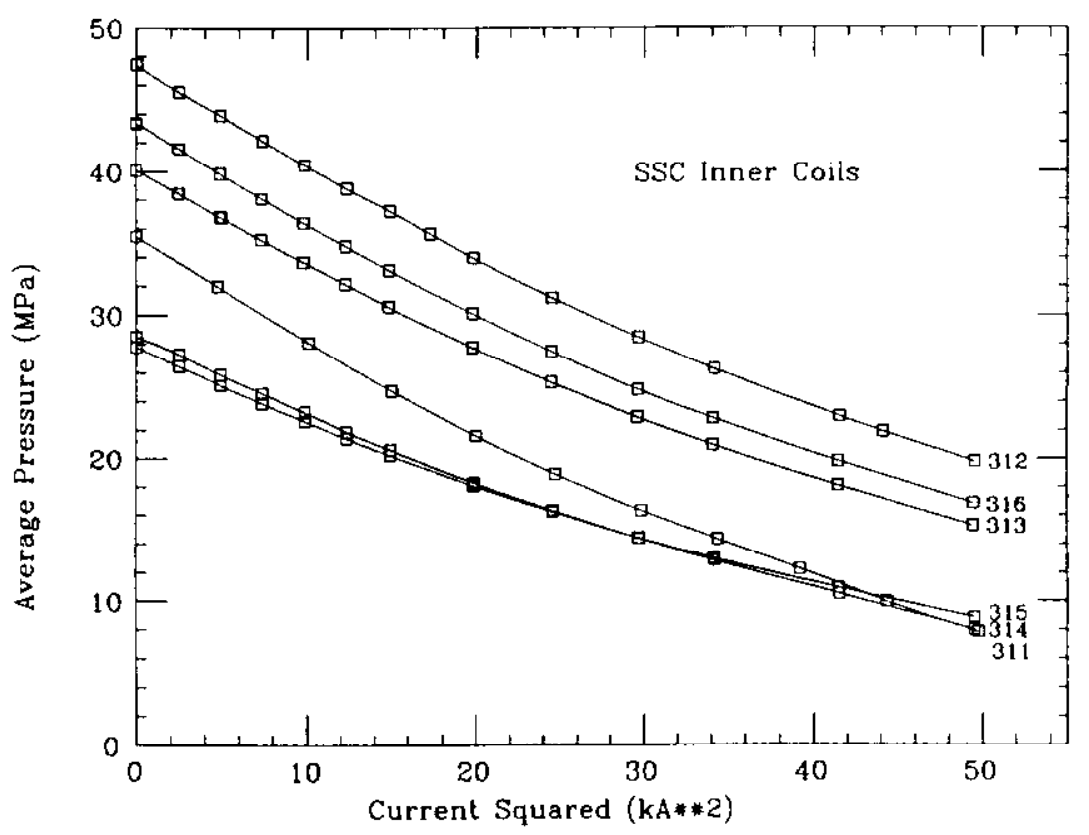

Fig. 4 Inner Coil Pressure During Excitation

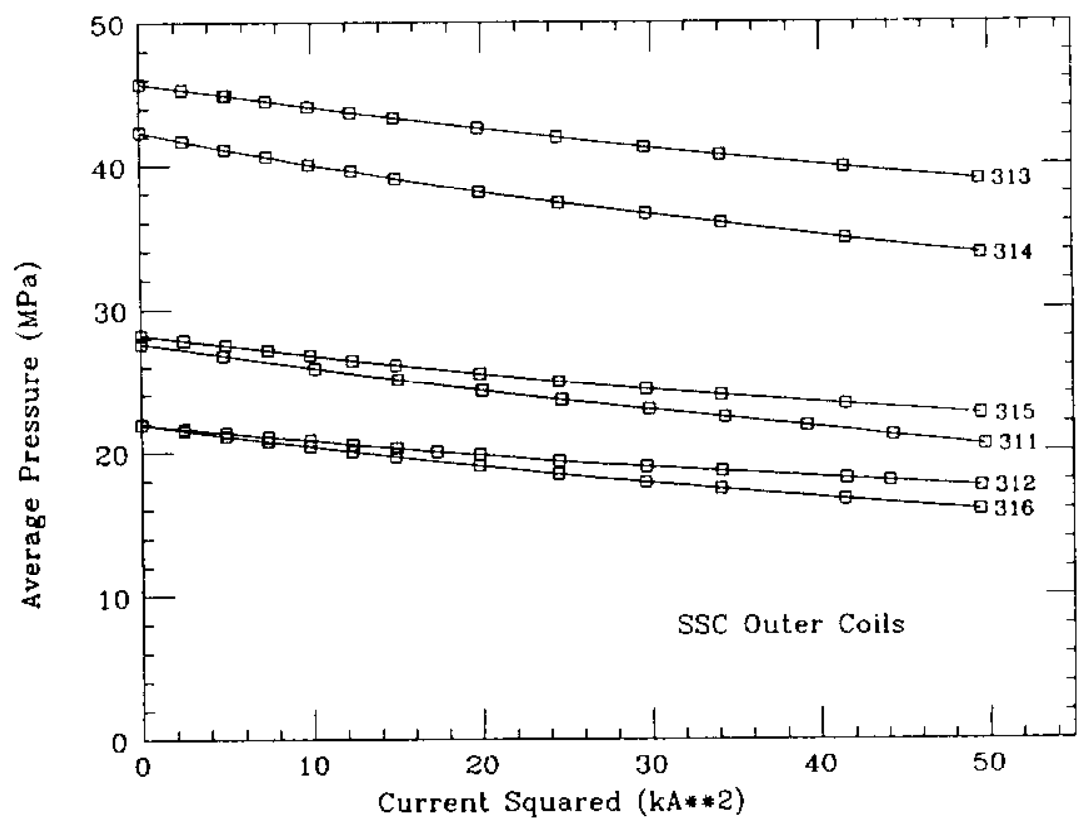

Fig. 5 Outer Coil Pressure During Excitation 
The yoke laminations of magnet DCA311 showed chevroning due to loose packing. The larger than average change in coil pressure with excitation current in the DCA311 data (especially the inner coils) is a reflection of the diminished support of the collars from the yoke in this magnet.

The change of pressure in the outer coil is much less than in the inner coil. Even though the magnetic field magnitude at the outer coil is less than that at the inner coil, the direction of the field is tilted more toward the horizontal plane. Therefore, the azimuthal component of the electromagnetic force in the outer coil should be at least $60 \%$ of the inner coil value. The small change of pressure with excitation in the outer coil can be explained if the collar is not making contact with the yoke in the vertical direction. The vertical spring constant of the coil-collar system is smaller than the horizontal one because there is no backup by the yoke. The outer coil is more influenced by the vertical motion of the collar because it occupies azimuthal angles close to the horizontal plane. This model is also supported by the fact that the effect of the chevroned yoke is not pronounced in the outer coils of DCA311.

The amount of pressure change in the inner coils is related to the initial pressure. In particular, magnets with large initial pressure tend to lose more pressure during magnet excitation, as shown in Fig. 6. The deformation of the coils is determined by the hoop stress and thickness of the collar and yoke. Therefore, the amount of deformation should not vary much between magnets, as the azimuthal strain observations discussed later verify. If the deformation is fixed, coils with high effective modulus of elasticity (implying large initial pressure) lose more pressure upon excitation. All magnets underwent excitation with a comfortable pre-load margin. The initial single training quenches of DCA313 and DCA314 might be related to unnecessarily large pre-load in the outer coils, which causes an imbalance of forces in the inner coils.

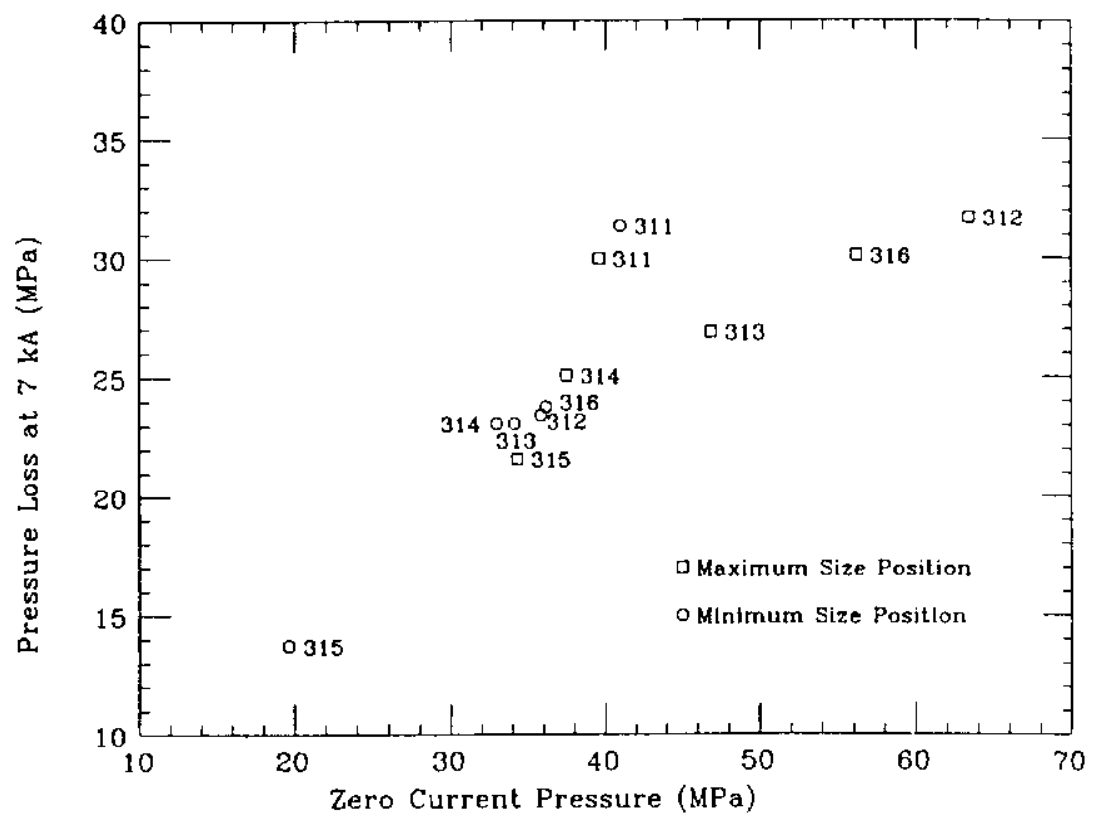

Fig. 6 Excitation Pressure Loss vs. Initial Pressure.

\section{END FORCE}

The magnet is partially supported in the axial direction at each end by sets of 4 stainless steel bullet slugs instrumented with strain gauges. Fig. 7 shows the total load experienced by the bullets in each magnet during the excitation. The end force increases in proportion to the current squared. However, only 10 to $15 \%$ of the total electromagnetic force $(100 \mathrm{kN}$ at 6.6 $\mathrm{T}$ ) is supported by the bullets.

Most of the axial electromagnetic forces were transferred to the yoke and shell through friction between the collar and yoke. The bullets were pre-loaded by adjusting bushing screws 
threaded into the end plates. Due to deformation of the end plate during welding, the initial loading of the DCA311 bullets was much larger than intended. On later magnets the initial bullet load was set low to take into account the increase during welding. Even in the extreme case of DCA311, the end force behavior measured by the bullets was not much different from that observed in the other magnets. Changes in bullet loads over thermal cycles were observed, but these changes were not drastic nor influential to quench performance.

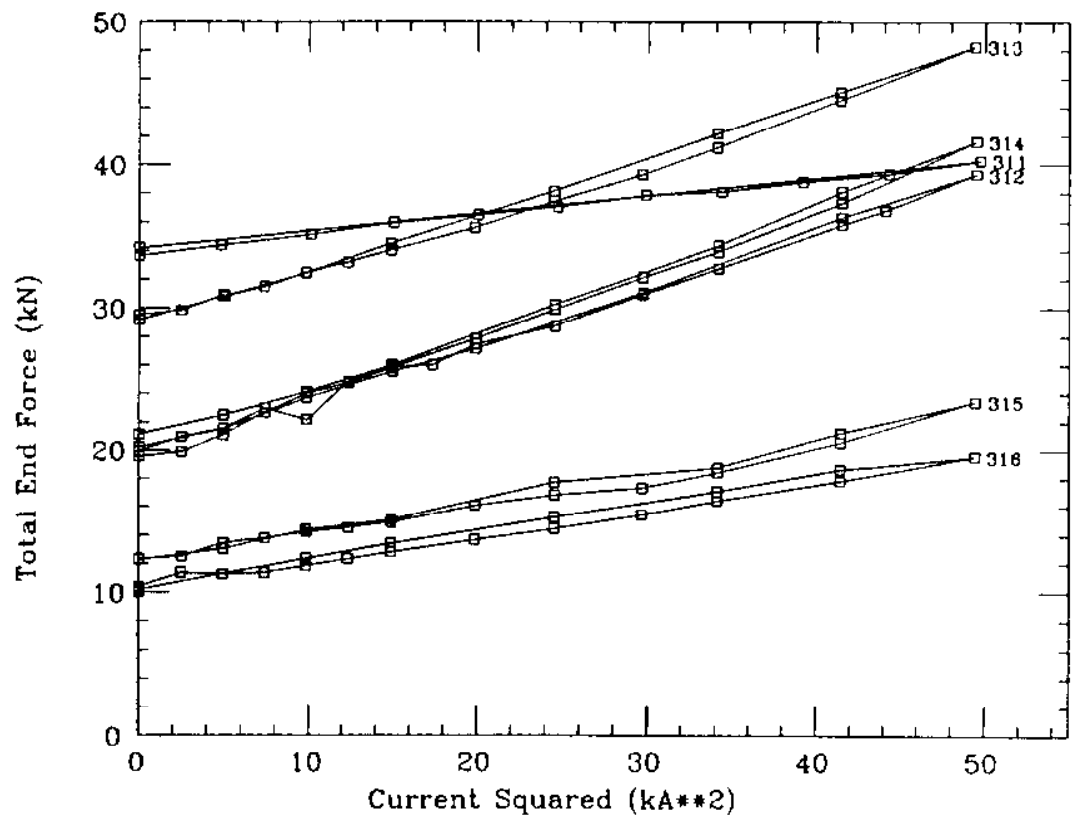

Fig. 7 End Force During Excitation Measured by Bullet Strain Gages. Sum of the loads in 4 bullets is plotted as total end force.

\section{AZIMUTHAL SHELL STRAIN}

The strain in the shell was also observed with strain gauges. The change in azimuthal shell strain during excitation is shown in Fig. 8 at different angles from the vertical plane. All of the magnets exhibited similar behavior. No change in the rate of strain increase with excitation was observed, as would have been the case if there were not enough pre-load in the shell. Strain measured at angles close to the vertical remains compressive, while the high angle gauges exhibit tensile strains. The strain profiles shown in Fig. 9 are quite different from the uniform distribution of tensile stress predicted by a simple hoop stress model. However, since these gauges were attached to the outer surface of the shell, they were sensitive to changes of curvature (bending) in addition to strains in the initial plane of the shell material. The major deformation inferred from the strain gauge data is therefore an ovalization in the horizontal plane. Such a deformation is understandable, because the electromagnetic force on the coil is mainly in the horizontal direction. The larger slope at angles near the parting plane could be due to bending of the yoke facilitated by the reduced stiffness in the vertical direction caused by the gap between yoke and collar.

The average stress, derived from the strains after Poisson correction, gives a value on the tensile side, but not more than a few $\mathrm{MPa}$ at $7 \mathrm{kA}$. The hoop stress of the electromagnetic force is apparently taken up by a decrease in the compression of the yoke, as designed. 


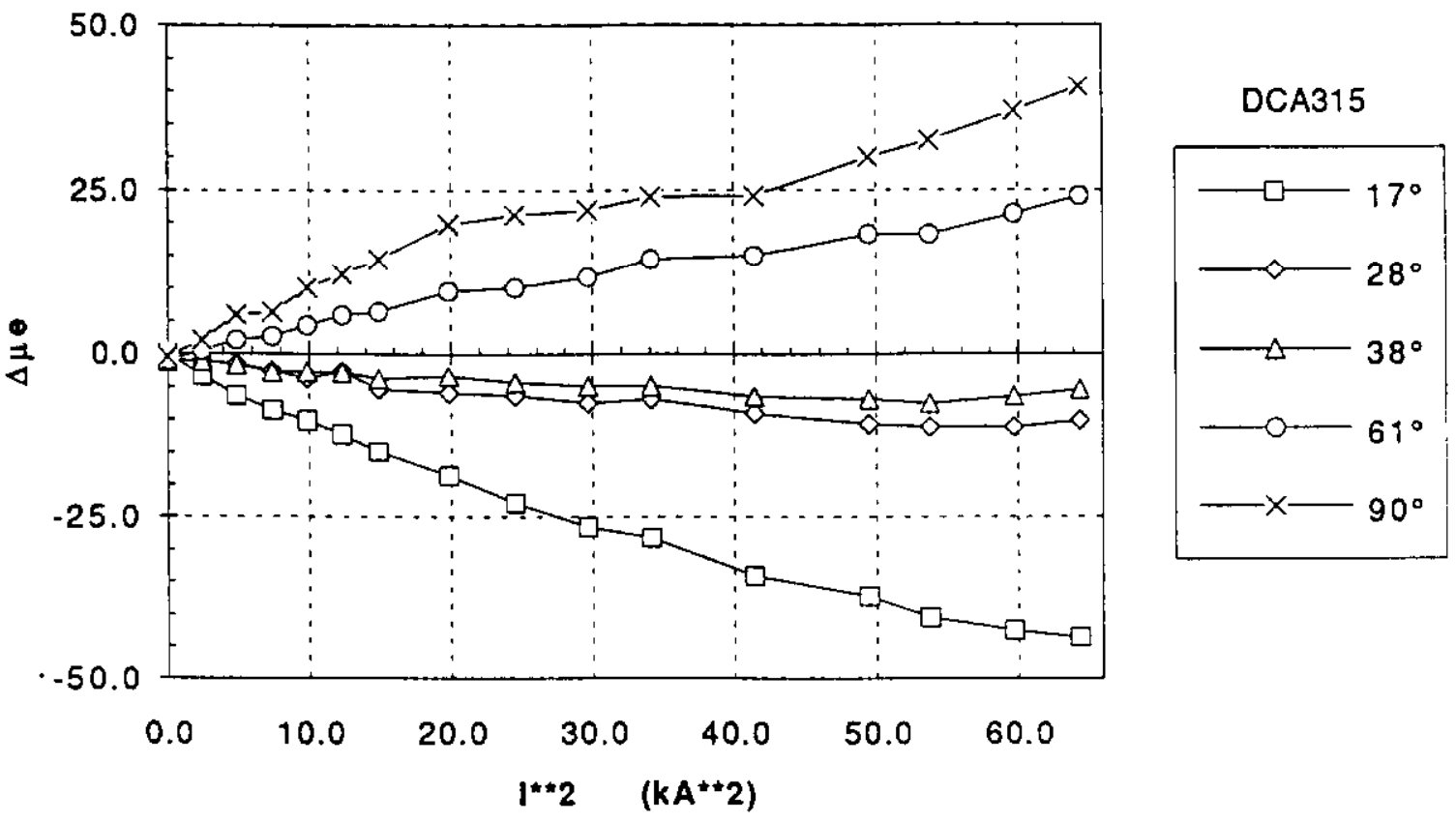

Fig. 8 Aximuthal Strain Change.

\section{AXIAL SHELL FORCE}

The shell has axial strain gauges mounted at 7 longitudinal positions. Fig. 9 is the stress profile of the axial force measured by these strain gauges. A simple spring model ${ }^{[5]}$ for both shell and coil, with coupling between these two springs provided by the deflection of the yoke and collar laminations or the sheer stress at material boundaries, predicts an exponential profile starting with the bullet force at each end and approaching some value at the center of the magnet. The overall profile of the axial strain can therefore be explained by this model. It is interesting that this transfer of the force to the shell takes place within the first $2 \mathrm{~m}$ of the end. The shell tension derived from observed strain at the center of the magnet indicates that $60 \%$ of the electromagnetic force is supported by the shell. The coils or other structures such as collaring keys take up the remaining $40 \%$ of the force. The posts may take some of the force as well.

The decrease in strain near the end is very large. In fact, the stress becomes compressive at the very end. This compressive stress is due to the absence of ovalization at the end of the magnet brought about by two causes: First, there is no radial force in this region to promote ovalization directly, and second, the end plate suppresses any ovalization which might take place. Close to the vertical plane, where the strain gages are mounted, the surface of the shell has to curve toward the outside approaching the end plate. This is why we observe an apparent compressive stress instead of the tensile stress expected from the bullets.

No significant hysteresis was observed in the axial stress. However, DCA313, DCA314, and DCA316, which showed some training, seem to have more negative values in the stress change at the end. The zero current strain at the very end also changed with thermal cycling. These deformations near the end might be related to the mechanism which brings about training.

\section{CONCLUSIONS}

The mechanics of a set of $15 m$ ASST SSC collider dipole magnets with vertically split yokes built at Fermilab have been explained using strain gauge data. All the observed mechanical behavior supports the effectiveness of the design principles of the ASST magnets. Detailed analysis might provide a clue toward solving the problem of occasional training quenches. 


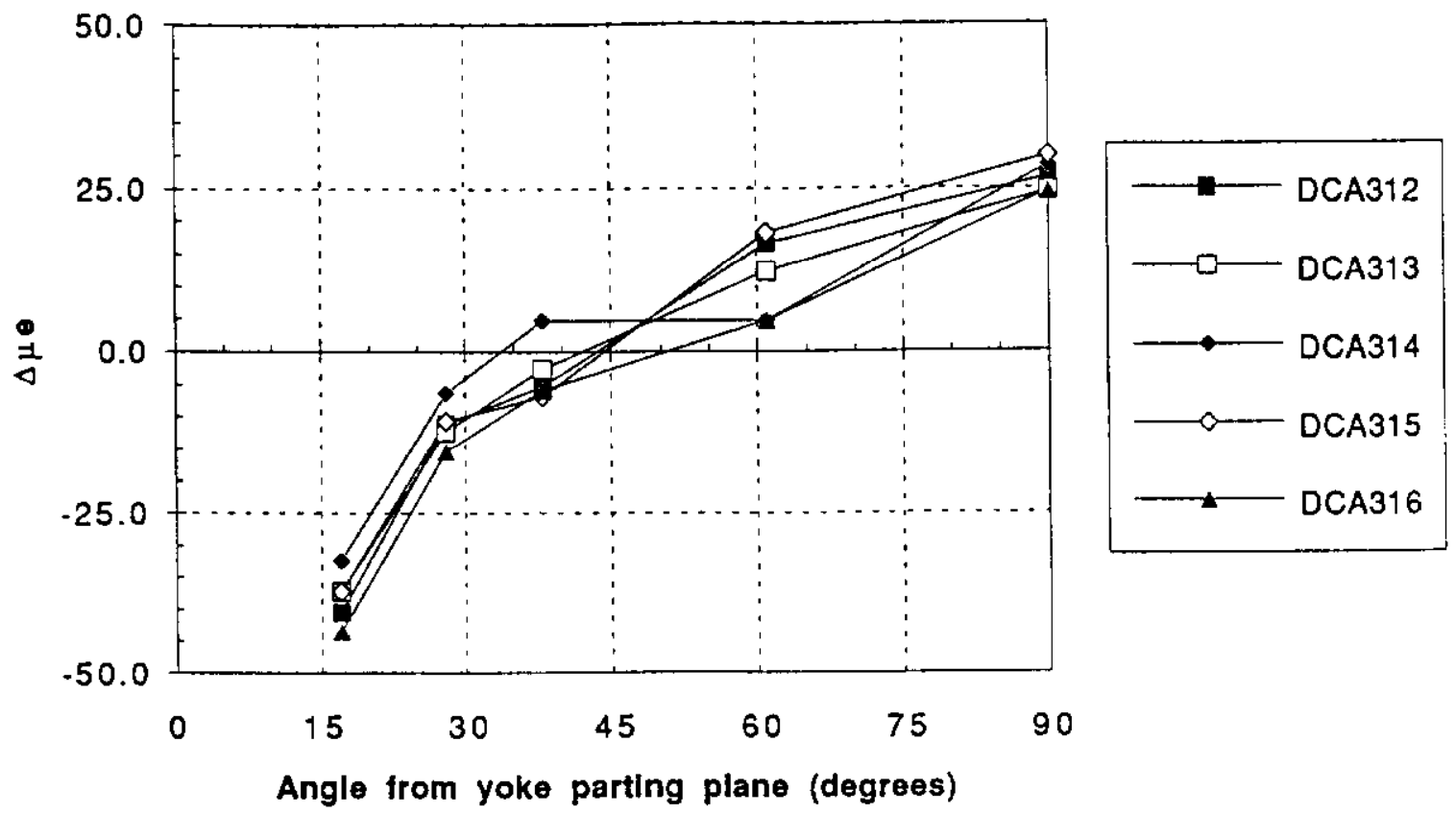

Fig. 9 Azimuthal Strain Profile.

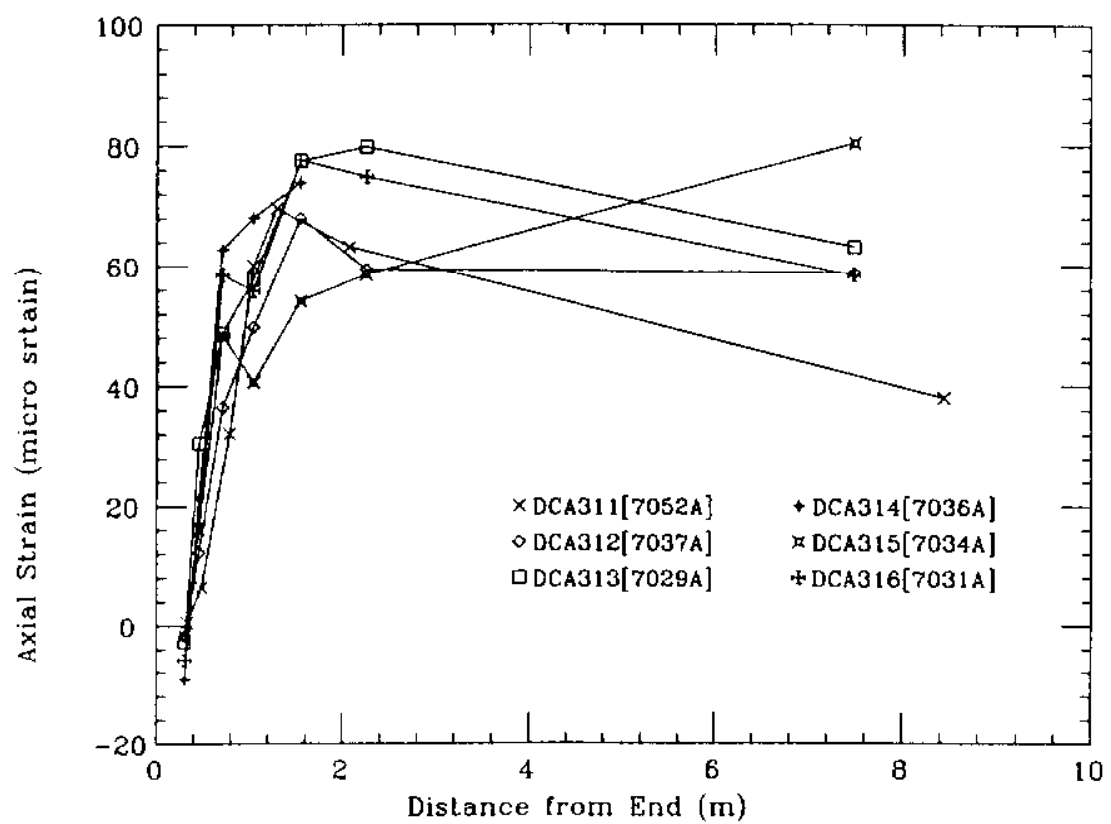

Fig. 10 Axial Strain Profile

\section{REFERENCES}

[1] R. C. Gupta et al., "SSC $50 \mathrm{~mm}$ Dipole Cross Section," Supercollider 3, p 587, J. Nonte (ed), Plenum Press, New York 1991.

[2] J.Strait et al., "Mechanical Design of 2D Cross-section of the SSC Collider Dipole Magnet," Proc. of IEEE Particle Accelerator Conference, San Francisco, p 2176, 1991.

[3] S.Delchamps et al., "SSC Collider Dipole Magnet End Mechanical Design," Proc. of IEEE Particle Accelerator Conference, San Francisco, p 2185, 1991.

[4] M.Wake, "Pressure-Size Diagram Update with DCA Series Long Magnet Data," Fermilab Technical Support Section Internal Note TS-SSC-91-254, 1991.

[5] M.Wake, "DCA313-316 Axial Strain Change," Fermilab Technical Support Section Internal Note TS-SSC-92-023, 1992. 